come back to us to be reinvested for the benefit of our patients. This would at once encourage thrift and improve our facilities.

RONALD LAW

London NW10

SIR,-In my experience it is not only general practitioners' surgeries where trivial complaints could well be reduced by education of the public (leading article, 11 December, p 1408). Accident and emergency departments today are besieged with persons whose bruises and sprains show a very low threshold of selfreliance and self-help and one which has become noticeably lower over the past few years-so much so that any little bump is another excuse to visit "mother's knee" in the shape of the local casualty department. The demand for an $x$-ray is made on the assumption that clinical examination is always fallible. Fear of litigation, though not yet as crippling in its effect on clinical morale here as in the USA, twists the casualty officer's arm to accede where even a lay person should be able to withstand such unnecessary pressure.

The GP faced with trivia has at least the compensation of "pastoral" contact with his own patient. The casualty officer who, as kindly as possible, tells the patient that there is nothing that time will not rapidly ameliorate is hard put to it to derive anything but frustration from the interview. Much more could be done to educate the public $(a)$ as to which injuries merit hospital attendance and $(b)$ as to the real function of the accident department, whose ability to deal with serious cases is constantly being sapped by time and energy spent on trivia.

Huddersfield

S L HENDERSON SMITH

\section{Vitamin D status in different subgroups of British Asians}

SIR,-We read with interest the article on this subject by Dr Sandra Hunt and her colleagues (4 December, $p$ 1351). We believe that the higher serum 25-hydroxycholecalciferol (25$\mathrm{OHD}_{3}$ ) concentrations in the Roman Catholic Goans compared with the Ismailis, Sikhs, Moslems, or Hindus may have a different explanation from the one they put forward. The most striking difference between the groups was that the Goans ate a Western-style diet while the other groups ate a traditional Eastern vegetarian diet. Recently it has been recognised that individuals who eat meat have a higher rate of drug oxidation than vegetarians, who, among other differences, have a lower protein intake. ${ }^{1}$ Taken together, these results make it probable that one of the limiting factors determining the plasma concentration of $25-\mathrm{OHD}_{3}$ is its rate of formation in the liver by inducible microsomal oxidation. In a study in which the rate of oxidation of antipyrine was related to diet, cigarette smoking, and other environmental factors the difference in rate between a vegetarian non-smoker and a meat-eating cigarette smoker was approximately two-fold. ${ }^{2}$ It is of great interest that the mean difference of serum $25-\mathrm{OHD}_{3}$ between the Goans and the rest is almos: exactly of that order. If this explanation is correct it would indicate that the predominant reason for the prevalence of vitamin D deficiency in the Asian community is not poor dietary intake of vitamin $\mathrm{D}$; rather that their traditional diet does not contain the factors in Western diet which compensate for the lack of sunlight by stimulating the mixed-function oxidase system of the liver.

This postulated mechanism is quite distinct from that occurring in anticonvulsant osteomalacia. In the latter case phenobarbitone and other agents are thought to divert the metabolism of cholecalciferol or $25-\mathrm{OHD}_{3}$ from normal pathways and thus produce a conditioned deficiency. ${ }^{3-5}$

C T DOLLERY H S FRASER DONALD Davies IAIN MACINTYRE

Department of Clinical Pharmacology

and Endocrine Unit,

Royal Postgraduate Medical School,

London $\mathrm{W} 12$

'Alvarez, A P, et al, Proceedings of the National Academy of Sciences of the USA, 1976, 73, 2501.

Fraser, H S, et al, Clinical Pharmacology and Thera-

peutics. In press.
Dent, C E, et al, British Medical fournal, 1970, 4, 69. Silver, J, Neale, G, and Thompson, G R, Clinical

Science and Molecular Medicine, 1974, 46, 433.
Hahn, T, et al, Journal of Clinical Investigation, 1972, 51, 741 .

SIR,-Dr Sandra P Hunt and her colleagues (4 December, $p$ 1351) have carried out painstaking investigations to determine serum 25-hydroxycholecalciferol levels in the various groups of British Asians and related these to the dietary intake of vitamin $\mathrm{D}$ and exposure of their bodies to the sunlight here in London.

For better interpretation of the results of the study it is important to specify whether the subgroup of Hindus included Gujratis or Panjabis or both. Comparatively speaking, the diet of the Panjabi/Hindu vegetarian is richer than that of his Gujrati counterpart. The former obtains his vitamin $D$ requirements from eggs, milk, butter, and cheese, while the latter consumes only small quantities of milk and butter. In addition, no mention is made of the educational and social class of the groups and subgroups included in the study. Generalisations without those considerations can be misleading.

Department of Community Health.
King's College Hospital.

M R BAHL

London SE5

\section{Asthma: Spinhaler usage warning}

SIR,-Prescribing physicians and pharmacists will be aware of the widespread usage of Intal (sodium cromoglycate) and Intal Compound (with isoprenaline) in the prophylactic treatment of asthma both in the UK and internationally.

Since the introduction of Intal in the UK in 1968 the Spinhaler device has been used regularly each day by many asthmatics without mishap. However, recently three case reports have been received by us-from the UK and Sweden-which demonstrate that the Spinhaler mouthpiece may become detached during Intal inhalation if it has not been firmly screwed home. Fortunately the patients did not suffer any ill effects but at the time the event was obviously alarming to them. Although the Spinhaler is a very safe device, since the events described are extremely rare, nevertheless we feel that patients (especially long-term Intal users) need to be reminded that it should be operated according to the manufacturer's instructions. Thus the patient must ensure that the mouthpiece is firmly screwed home and checked before inhaling Intal from the device.

Future product packs and accompanying literature will emphasise this requirement. We request the assistance of all prescribing physicians to bring this warning to the attention of all patients taking Intal as soon as possible so that the events recently reported do not recur.

D C QUANTOCK Director of Medical Affairs,
Fisons Ltd Pharmaceutical Division

Loughborough, Leics

\section{Metronidazole and anaerobic sepsis}

SIR,-We would like to apologise to our colleagues in Newcastle for inadvertently referring in our recent paper (11 December, p 1418, ref 14) to a case report of their use of intravenous metronidazole in brain abscess rather than to their report of more extensive use of both oral and intravenous preparations of the drug in anaerobic infection. ${ }^{1}$ Like us, they achieved good results and observed no evidence of toxicity with the intravenous preparation.

SUSANNAH EYKYN IAN PHILlips

Department of Microbiology,

St Thomas's Hospital Medical

School,

' Selkon, J B, Hale, J H, and Ingham, $M$ R, in Chemotherapy: Proceedings of the 9th International Conference, London, vol 1 , ed $\mathrm{J} D \mathrm{D}$ Williams and $\mathrm{A} M$ Geddes, $p$ 277. New York and London, Plenum
Press, 1976.

SIR,-I was surprised that Dr Susannah J Eykyn and Dr I Phillips (11 December, p 1418) reported no side effects with metronidazole.

In a pilot study I have treated 19 patients (six with small-bowel diverticulosis and 13 with Crohn's disease) for intestinal bacterial overgrowth with oral metronidazole $(200 \mathrm{mg}$ 8-hourly) for four weeks. Eight were unable to tolerate the drug, complaining variously of severe lethargy, anorexia, nausea, and a sore, furred tongue. These complications usually occurred after one week of therapy, while the serum levels were within the range $8-16 \mathrm{mg} / \mathrm{l}$.

J H B SCARPELlo

Royal Infirmary,

Sheffield

\section{Oestrogens for menopausal flushing}

SIR,-We wish to draw to the attention of Dr G P Mulley and Professor J R A Mitchell (16 October, p 944) and Professor L A Klopper (30 October, p 1069) the results of our two double-blind randomised cross-over placebo trials $^{12}$ on the effect of conjugated equine oestrogens (Premarin $1.25 \mathrm{mg}$ ) on the psychological and symptomatic status, including vasomotor instability, of peri- and post-menopausal women. 
Of 64 patients with severe menopausal symptoms who were allocated to a four-month trial in which Premarin and placebo were each taken for two months, 44 had severe vasomotor symptoms; a further 56 patients with less severe symptoms were allocated to a longer, 12 month trial in which Premarin and placebo were each taken for six months. It is stressed that neither the patients nor the attending doctors knew which treatment was being given. Graphic rating scales, 34 which are a widely accepted and sensitive method of measuring change, were used to assess the effects of therapy, and thus the argument that a flush count is not an objective way of evaluating therapy cannot apply to these trials.

During placebo therapy, with respect to control values, there was a small, nonsignificant reduction in hot flushes in patients on the four-month trial, and in patients on the 12 -month trial this reduction was just statistically significant $(P<0 \cdot 05)$. However, during oestrogen therapy, with respect to placebo values, there was a statistically significant reduction in hot flushes in patients on both the four-month $(P<0.001)$ and 12month $(P<0.001)$ trials.

Furthermore, in the 64 patients on the fourmonth trial benefits of oestrogen therapy over placebo were observed for 11 additional symptoms. The improvement in such a large number of symptoms is to some extent a domino effect-that is, a reduction in vasomotor symptoms creates a favourable response in a large number of associated symptoms. This could be demonstrated by studying the 20 patients who had severe menopausal symptoms but no hot flushes; in this group significant improvements on oestrogen therapy were observed for only five (vaginal dryness, memory, anxiety, worry about self, and worry about age) of the 11 additional symptoms. However, the improvement in memory and anxiety in this subgroup suggests that the "mental tonic" effect of oestrogens described by Utian' is an entity and is independent of vasomotor symptoms.

The dearth of good placebo studies on the evaluation of oestrogen therapy in the treatment of the menopausal syndrome initiated these trials. Our results indicate that a significant reduction in hot flushes and a significant improvement in wellbeing, both psychological and symptomatic, will be achieved by oestrogen therapy.

STUART CAMPBELI $M$ WHITEHEAD

Department of Obstetrics and

Kynaecology,
School,

London SE

1 Campbell, S, et al, in Management of the Menopausal and Postmenopausal Years, ed S Campbell, p 149. and Postmenopausal Year

${ }^{2}$ Campbell, $S$, and Whitehead, $M$, in Clinics in Obstetric and Gynaecology, vol 4, No 1, ed R Greenblatt and J Studd. Philadelphia, Saunders. In press.

Guilford, S, Psychometric Methods. New York, 1936. Lader, M H, and Wing, L, Physiological Measures, Sedative Drugs and Morbid Anxiety. Institute of Pychiatry Maudsley Monographs. London, Oxford University Press, 1966

Utian, $\mathrm{W}$ H, in Frontiers in Hormone Research Oestrogens in the Postmenopause, ed P A van Keep

\section{Clonidine and facial flushing in rosacea}

SIR,-A recent survey in this department ${ }^{1}$ showed an association between migraine and rosacea, $44 \%$ of patients with rosacea having migraine, compared with only $13 \%$ of control subjects. As both conditions are associated with abnormal vascular reactivity, drugs which are helpful in migraine could be of benefit in rosacea. In that same paper it was suggested that low doses of clonidine might reduce facial flushing. It was therefore decided to perform an oral and topical double-blind trial of clonidine in the treatment of rosacea with particular reference to flushing.

Seventeen patients entered the oral trial, which lasted for six months; all subjects had rosacea with some degree of facial erythema and flushing and were given either clonidine $0.05 \mathrm{mg}$ twice daily or matched placebo tablets, the therapy being crossed over after three months. Twenty rosacea patients in whom flushing was the main feature entered the topical trial, in which $2^{\circ}{ }^{\circ}$ clonidine in a cream base was applied to one side of the cheek and the base alone to the other side four times daily for two weeks.

Both oral and topical active therapies were, on the whole, without effect, but five patients in the oral trial did notice an improvement in the frequency and severity of their attacks of facial flushing while on clonidine. In four patients with severe rosacea the oral trial had to be stopped because of a flare-up of the pustular element of their rosacea. In three of these patients this occurred during the threemonth clonidine regimen. The lack of effect of the topical therapy could be due either to clonidine as a drug being totally ineffective in this condition or, alternatively, to the base in which the clonidine was incorporated being inappropriate.

From this evidence it would seem that there is no place for clonidine therapy in the routine treatment of rosacea, but it may occasionally be of benefit to patients whose predominant feature is flushing.

W J CUNLIFFE BARBARA DODMAN Department of Dermatology, JULia G BINNER

General Infirmary,

Leeds

Tan, S G, and Cunliffe, W J, British Medical fournal, $1976,1,21$.

\section{D-Penicillamine and fatal obliterative} bronchiolitis

SIR,-As stated by Dr D A Brewerton (18 December, $p$ 1507), the death from obliterative bronchiolitis of four patients with rheumatoid arthritis was reported recently at a meeting of the Heberden Society. Two of these patients had been given D-penicillamine for their arthritis at Westminster Hospital, where some 60 rheumatoid patients had been maintained on the drug, and two had not.

In order to find out whether the same sort of thing was happening elsewhere I wrote to those in charge of 37 clinics asking (a) for the approximate numbers of patients who had received penicillamine for more than six

Mortality of patients under treatment with $\mathrm{D}$-penicillamine

\begin{tabular}{|c|c|c|c|c|}
\hline & $\begin{array}{l}\text { Approximate No } \\
\text { of patients } \\
\text { treated }\end{array}$ & $\begin{array}{c}\text { Deaths } \\
\text { (all causes) }\end{array}$ & $\begin{array}{l}\text { Deaths from } \\
\text { non-acute } \\
\text { cardiopulmonary } \\
\text { disease }\end{array}$ & $\begin{array}{l}\text { Deaths from } \\
\text { obliterative } \\
\text { bronchiolitis }\end{array}$ \\
\hline 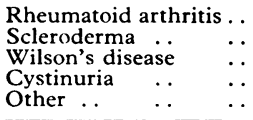 & $\begin{array}{r}2861 \\
76 \\
300 \\
69 \\
50\end{array}$ & $\begin{array}{r}64 \\
8 \\
37 \\
3 \\
0\end{array}$ & $\begin{array}{l}8 \\
6 \\
0 \\
1 \\
0\end{array}$ & $\begin{array}{l}2 \text { ( }+1 \text { uncertain) } \\
0 \\
0 \\
1 \text { (uncertain) } \\
0\end{array}$ \\
\hline Total & 3356 & 112 & 15 & 4 \\
\hline
\end{tabular}

months, (b) for the mortality (from all causes) among them, and (c) for the numbers of such deaths that were from cardiopulmonary disease, excluding acute myocardial infarction.

The results of this inquiry are summarised in the accompanying table. The relatively high mortality from Wilson's disease and scleroderma is almost entirely the result of failures of the drug to control these diseases. Note also that most of the patients with Wilson's disease or cystinuria have been taking penicillamine for many years (up to 21), whereas most of the others have been on it for less than two years. Of the 15 non-acute pulmonary deaths, only two were definitely attributable to obliterative bronchiolitis and these were the two at Westminster Hospital. This diagnosis remains a possibility in two more, though an unlikely one in the case of the cystinuric patient.

There is therefore no reason to suppose that penicillamine causes death from obliterative bronchiolitis.

This letter has been drafted with the help of those who contributed the data upon which it is based, for which much thanks.

W H LYLE Medical Director,
Dista Products I,td

\section{Speke,}

\section{Prostatic cancer}

SIR,-We agree with Dr A Rostom (16 October, p 942) and Mr E P N O'Donoghue and Mr G D Chisholm (27 November, p 1324) on the need to improve the treatment of carcinoma of the prostate. We also agree that lymphography is not necessarily a sufficiently accurate technique on which to base a therapeutic protocol. ${ }^{1} \mathrm{We}$ are, however, concerned that clinical trials are apparently being considered for so-called "localised" prostatic carcinoma involving as a basis for therapeutic protocols currently available techniques to fulfil TNM requirements for classification. As with virtually every other solid tumour, the whole problem of prostatic carcinoma is that therapeutically essential staging - that is, the distinction between those patients who have truly localised or regional disease as distinct from those who have disseminated micrometastases not detectable by current screening methods-is not possible at present. The concept that this therapeutically vital distinction cannot be made is not recent, having been pointed out by Franks in $1956,{ }^{2}$ and the same problem also applies to other tumours such as lung, breast, and head and neck cancers.

In our opinion any logical trial aimed at improving the survival time in prostatic cancer such as surgery or radiotherapy with local therapy plus systemic therapy with antitumour drugs. It is a depressing fact that only $10 \%$ of the currently available antitumour drugs should compare local or regional techniques 